American Journal of Animal and Veterinary Sciences 3 (3): 73-77, 2008

ISSN $1557-4555$

(C) 2008 Science Publications

\title{
Ultrasonographic Evaluation of Transcutaneous Electrical Neural Stimulation on the Repair of Severed Superficial Digital Flexor Tendon in Horses
}

\author{
${ }^{1}$ Davood Sharifi, ${ }^{2}$ Dauod Kazemi and ${ }^{1}$ Abbas Veshkini \\ ${ }^{1}$ Department of Clinical Sciences, Surgery and Radiology Section, \\ Faculty of Veterinary Medicine, University of Tehran, Iran \\ ${ }^{2}$ Department of Clinical Sciences, Surgery and Radiology Section. \\ Faculty of Veterinary Medicine, Islamic Azad University, Tabriz Branch, Tabriz, Iran
}

\begin{abstract}
Problem statement: The main aim was to clinical assessment of the ultrasonographic changes of transcutaneous electrical neural stimulation after inducing injury in the SDFT in horses. Approach: Using 8 adults' castrated horses having 350-550 Kgbw with 4-6 years of age. The left hind limb and right fore-limb Superficial Digital Flexor Tendon (SDFT) were splitted longitudinally at mid metatarsal and metacarpal regions in full thickness of $10 \mathrm{~cm}$ in length using B.P.blade 15 time strikes, then the connective tissue and skin was approximated using No 2 Nylon. Horses were divided into two groups of control and treated with 4 horses each. No treatment was given to control one, whereas treated group was subjected to transcutaneous neural electrical stimulation for 10 min daily with intensity of $80 \mu \mathrm{s}$ and $100 \mathrm{~Hz}$ frequency over 14 days using TENS apparatus newtens 900c. Ultrasonograhic examination was done using Pie Medical 200 Vet Apparatus in 0, 7, 14, 21, 28, 45 and 60 days measuring Cross-Sectional Area (CSA) of SDFT in operated limbs in each horse. For assessing the variation in this finding the Repeated Measure Analysis of Variance was used. Results: After comparing the healing process between two groups, it was significantly accelerated in treated with therapeutic ultrasound. Pain relief, swelling, tenderness, heat and functional recovery in treated with therapeutic ultrasound significantly improved comparing to control group. There was significant effect on reducing lameness in treated group by 28 days after splitting, whereas lameness persisted till 60 days in control group. Ultrasonography findings showed significant decrease in SDFT diameters and Cross Sectional Area (CSA) in the treated limbs comparing with control. Conclusion: Clinically speeding wound healing beside complete reduction of swelling, pain and lameness, its application significantly accelerated functional recovery affected limb.
\end{abstract}

Key words: Ultrasonography, TENS-horse, tendon

\section{INTRODUCTION}

Tendon injuries and severe fibrous tearing is often the result of sudden jerk and physical weight bearing strain overload by the soft tissue support of the distal limb. It is commonly recognized in racing and jumping horses, conformation can exacerbate an individual horse's propensity to tendinitis. Long sloping pasterns, long toes, over at the knees and tied in knees can increase the forces at the flexor surface when extreme extension is required by the limb. This injury may be caused by degenerative changes resulting from continued stress ${ }^{[1,5,7-9,20]}$ or by mechanical damage from horseshoes, stall doors, farm machinery, or wire cut and healing of tendon lesions is usually protracted and complete functional restoration is $\operatorname{rare}^{[1,9]}$ The
Superficial Digital Flexor Tendon (SDFT) is most commonly affected and the incidence of reinjury in this tendon is relatively $\operatorname{high}^{[1,2]}$. Diagnostic ultrasonography has been established as the imaging technique of choice to confirm the presence or absence of an injured superficial digital flexor tendon by qualitatively identifying hypoechoic fiber bundles ${ }^{[1,5,10]}$. The collective ultrasonographic data have the potential to categorized tendon injuries when the prognosis is given for future racing. so the purpose of this study was to compare the effect of the local application of transcutaneous electrical nerve stimulation on healing of severed SDFT healing with that of treated conservatively (controlled one). It also gave the opportunity to compare the rate of reinjury in horses used for different athletic purposes.

Corresponding Author: Davood Sharifi, Department of Clinical Sciences, Surgery and Radiology Section, Faculty of Veterinary Medicine, University of Tehran, Iran 


\section{MATERIALS AND METHODS}

In this study, effects of therapeutic transcutaneous electrical nerve stimulation on experimentally induced severe injury on superficial flexor tendon in horses were evaluated by clinical, ultrasonographical, histomorphological and histobiochemical parameters. Eight adults mixed breed, clinically healthy horses, 49 years old with weight range of $350-550 \mathrm{Kg}$ were used. Full thickness in $10 \mathrm{~cm}$ in length of midsection of SDFT on left hind limb and right fore limb was splitted 15 strikes using surgical blade (Fig. 1), then animals were divided into two groups of 4 horses in each group randomly. In group I control no treatment was used. whereas treated group was subjected to transcutaneous electrical neural stimulation for $10 \mathrm{~min}$ daily with intensity of $80 \mu \mathrm{s}$ and $100 \mathrm{~Hz}$ frequency over 14 days using TENS apparatus (newtens 900c) (Fig. 2).

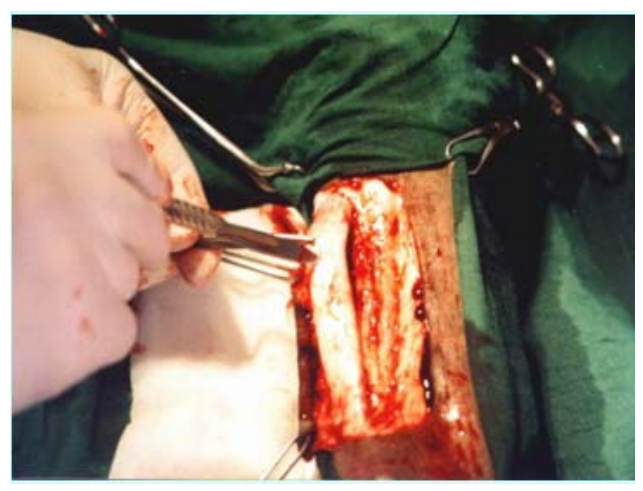

Fig. 1: Splitting full thickness of SDFT

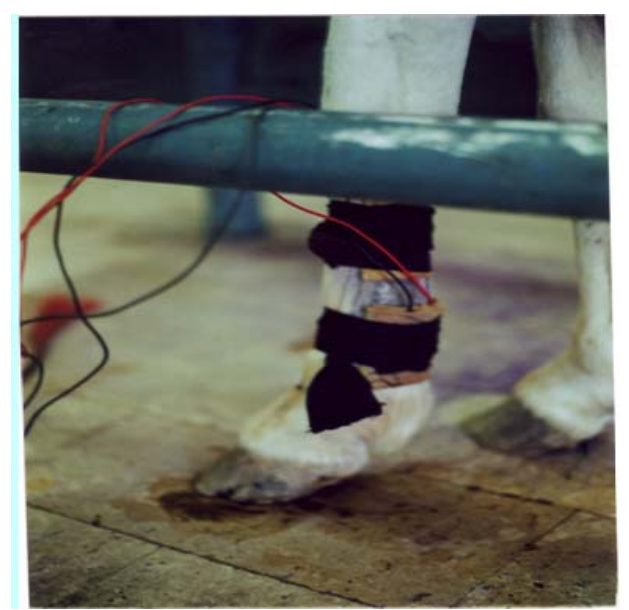

Fig. 2: Proper position and placement of surface electrodes on the upper and lower parts of splitted area
Ultrasonograhy recording was done using Pie Medical 200 Vet Apparatus on 0, 7, 14, 21, 28, 45 and 60 days measuring Cross-Sectional Area (CSA) of SDFT of both operated limbs in each horse. For assessing the variation in this finding the Repeated Measure Analysis of Variance was used and for better evaluation grading from 0 (immediate after splitting) to 4 (normal echo) were used.

\section{RESULTS}

After comparing the healing process between normal (Fig. 3), control and treated groups (Fig. 4 and 5). it was significantly accelerated in treated tendon with TENS. Pain relief, swelling, tenderness, heat and functional recovery in treated limbs with TENS significantly improved comparing to control group. There was significant effect on reducing lameness in treated group by 28 days after splitting, whereas lameness persisted till 60 days in control group.

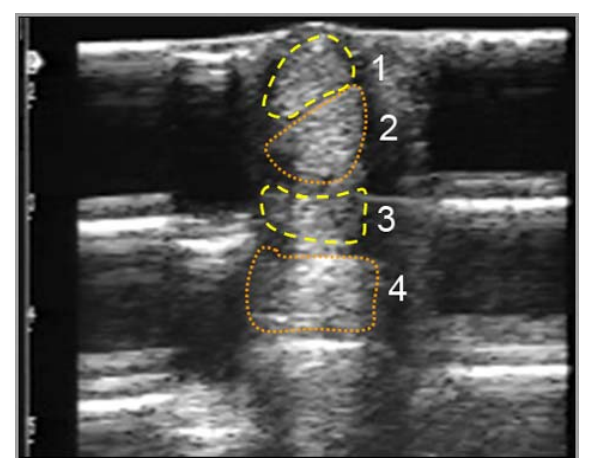

Fig. 3: Ultrasonography of normal SDFT (normal echogenic of SDFT (1), DDFT (2), Cruciate Ligament (3) and suspensory ligament (4))

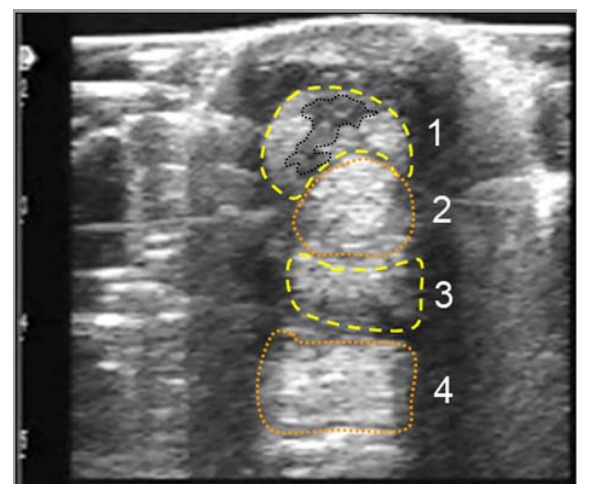

Fig. 4: Ultrasonography on 7th day showing increase in thickness and decrease echogenicity with peritendinitis and centrally located core lesion inside the SDFT (1) in treated limb 


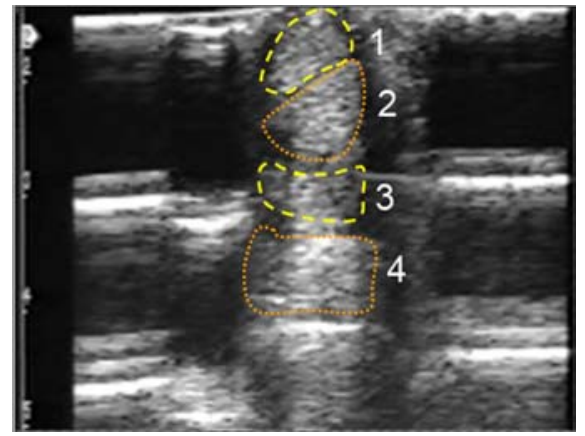

Fig. 5: Ultrasonography on 60 days showing improved echogenicity and reduced central defect in treated limb

The injured SDFT was grossly thickened over $10 \mathrm{~cm}$ of the length at the site of splitting and ultrasonographic images showed an extensive hypoechoic core and in sagittal plane, the thickness of SDFT was also quite evident with predominately granular hypoechoic in the injured area in control limb. On 7th day there were grade 3 echogenicity in both control and treated limb (Fig .4) whereas in treated one on 14 day it was reduced to 2 and even to 1.25 grade on 21 st day which showed normal echogenicity in treated group on day 28 and 60 days (Fig. 5) after splitting and treatment. But no changes were observed in control ones, therefore there was significant decrease in SDFT diameters and Cross Sectional Area (CSA) in the treated limbs comparing with control one. No ultrasonographical abnormalities were detected in the other part of tendon.

\section{DISCUSSION}

Traditional therapy and Transcutaneous Electrical Nerve Stimulation (TENS) and other similar devices use a mild form of electrically-induced pain to block the body's ability to perceive the pain that is being treated ${ }^{[2-4]}$. When patients receive TENS at low frequencies (eight pulses per second or less), their production of endorphins may increase, thus producing temporary relief. The effect of TENS is believed to stimulate A-b (beta) pain-suppressing nerve fibers to overwhelm chronic pain carrying $\mathrm{C}$ fibers.

Massage, ice and heat also relieve pain this way ${ }^{[18]}$. TENS and high-voltage pulsed galvanic stimulators deliver currents in the milliamperage range; this stimulation generally exceeds the nerve firing threshold, resulting in sensation ranging from a gentle tingling to intense muscle throbbing ${ }^{[13,22,24]}$. Traditional TENS only works if the current is strong enough to feel, which can result in the administered current being as strong as 80 milliamperes. Increasing the current causes mild electrical burns in about one third of the patients and the technique provides no significant residual effects in tissue healing ${ }^{[12]}$. In this study the ultrasonographical observations of the injured SDFT correlated well with the histopathological findings. The disrupted bundles of tendon fibers, which acted as diffuse rather than specular reflectors ${ }^{[17]}$. The fibroblast containing hyper cellular tracts and occasional fresh hemorrhagic foci ${ }^{[28]}$ all contributed to the observed hypoechogenic areas in the tendon ${ }^{[14,15]}$. During the 8 weeks period of observation the injured SDFT was at the early maturation phase of tendon healing. The progressive increase in tendon echogenicity was related to a gradual reorientation of the bundles of tendon fibers along the lines of stress of tendon ${ }^{[26-28]}$ so that the reoreintated bundles now acted as specular reflectors. The increase in the acoustic density of the tendon fibers bundles was due to increase in the number of intermolecular and intermolecular linkages in the collagen fibers ${ }^{[33]}$ and even a decrease in the number of fibroblasts. The extent of tendon and ligament injuries has been based on a qualitative assessment of their echogenicity ${ }^{[25,29]}$. A more detailed method of determining the severity of a tendon or ligament injury and the prognosis for repair was suggested ${ }^{[6,7,11,16]}$. They proposed the recordings be made of the percentage of the cross-sectional area that was damaged in the tendon or ligament, the length of the lesion and whether the origin or insertion of the tendon or ligament was involved $^{[14,19,21,23]}$ recorded the percentage cross sectional area of the damaged part of SDFT and multiplied them firstly by the scaling factor of 0.025.The resultant "severity rating" was used to provide information on the extent of tendon injury and to give a prognosis for satisfactory return to racing. In this study, the effect of TENS ${ }^{[30-32]}$ and accuracy of the ultrasonographic examination ${ }^{[26]}$ could be further increased by including a quantitative, rather than a qualitative measurement of tendon or ligament echogenicity.

\section{CONCLUSION}

Ultrasonographic findings can be regarded as good clinical indication for normalization of injured tendon.

\section{REFERENCES}

1. Buchanan, C.I. and R.L. Marsh, 2002. Effects of exercise on the biomechanical, biochemical and structural properties of tendons. Comparat. Biochem. Physiol. Part A: Mol. Integrat. Physiol., 133: 1101-1107. http://cat.inist.fr/?aModele $=$ afficheN\&cpsidt $=1441$ 2264. 
2. Burssens, P., R. Forsyth, A. Steyaert, E.V. Ovost, M. Praet and R. Verdonk, 2003. Influence of burst TENS stimulation on the healing of Achilles tendon suture in man. Acta Orthopaedca Belgica, 69:

528-532.

http://www.actaorthopaedica.be/acta/article.asp?lan $\mathrm{g}=$ en\&navid $=244 \& \mathrm{id}=630 \& \bmod =$ Acta.

3. Burssens, P., R. Forsyth, A. Steyaert, E.V. Ovost, M. Praet and R. Verdonk, 2005. Influence of burst TENS stimulation on collagen formation after Achilles tendon suture in man. A histological evaluation with Movat's pentachrome stain. Acta Orthopaedica Belgica, 71: 342-346. http://www.ncbi.nlm.nih.gov/pubmed/16035709.

4. Cramp, A.F.L., C. Gilsenan, A.S. Lowe and D.M. Walsh, 2000. The effect of high and low frequency transcutaneous electrical nerve stimulation upon cutaneous blood flow and skin temperature in healthy subjects. Clin. Physiol., 20: $\quad 150-157$. DOI: $10.1046 /$ j. $1365-$ 2281.2000.00240.x.

5. Dowling, B.A., A.J. Dart, D.R. Hodgson and R.K.W. Smith, 2000. Superficial digital flexor tendonitis in the horse. Equine Vet. J., 32: 369-378. http://www.ingentaconnect.com/content/evj/evj/20 00/00000032/00000005/art00003.

6. Dowling, B.A. and A.J. Dart, 2005. Mechanical and functional properties of the equine superficial digital flexor tendon. Vet. J., 170: 184-192. http://www.ncbi.nlm.nih.gov/pubmed/16129339?d opt $=$ Abstract.

7. Dyson, S.J., 2004. Medical management of superficial digital flexor tendonitis: A comparative study in 219 horses (1992-2000). Equine Vet. J., 36:

415-419.

http://www.ingentaconnect.com/content/evj/evj/20

04/00000036/00000005/art00008;jsessionid=40rlm tmkk6tjc.alice?format=print.

8. Eddy, A.L., L.M. Van Hoogmoed and J.R. Snyder, 2001. The role of thermography in the management of equine lameness. Vet. J., 162: 172-181. http://www.ncbi.nlm.nih.gov/pubmed/11681868.

9. Ehrlich, H.P., P.A. Lambert, G.C. Saggers, R.L. Myers and R.M. Hauk, 2005. Dynamic changes appearing in collagen fibers during intrinsic tendon repair. Ann. Plast. Surg., 54: 201-206. http://www.ncbi.nlm.nih.gov/pubmed/15655474.

10. Enwemeka, C.S., 1989. Inflammation, cellularity and fibrillogenesis in regenerating tendon: Implications for tendon rehabilitation. Phys. Therap., $\quad$ 69: 816-825. http://www.ncbi.nlm.nih.gov/pubmed/2780808.
11. Farkas, L.G., M.A. Herbert and J.S. James, 1980. Peritendinous healing after early movement of repaired flexor tendon: Anatomical study. Ann. Plast. $\quad$ Surg., $\quad$ 5: 298-304. http://www.ncbi.nlm.nih.gov/pubmed/6985509?do $\mathrm{pt}=$ Abstract.

12. Frick, A. and D. McCauley, 2005. Microcurrent electrical therapy. J. Equine Vet. Sci., 25: 418-422. http://linkinghub.elsevier.com/retrieve/pii/S073708 0605003886.

13. Fujita, M., S. Hukuda and Y. Doida, 1992. The effect of constant direct electrical current on intrinsic healing in the flexor tendon in vitro. An ultrastructural study of differing attitudes in epitenon cells and tenocytes. Br. J. Hand Surg., 17: 94-98. DOI: 10.1016/0266-7681(92)90021-S

14. Gillis, C., D.M. Meagher, A. Cloninger, L. Locatelli and N. Willits, 1995. Ultrasonographic cross-sectional area and mean echogenicity of the superficial and deep digital flexor tendons in 50 trained Thoroughbred racehorses. Am. J. Vet. Res., 56 :

1265-1269.

http://cat.inist.fr/?aModele $=$ afficheN\&cpsidt $=1073$ 9657.

15. Gillis, C., N. Sharkey, S.M. Stover, R.R. Pool, D.M. Meagher and N. Willits, 1995. Ultrasonography as a method to determine tendon cross-sectional area. Am. J. Vet. Res., 56: $\quad$ 1270-1274. http://www.ncbi.nlm.nih.gov/pubmed/8928941.

16. Henninger, R., 1994. Treatment of superficial digital flexor tendinitis. Vet. Clin. North Am.: Equine $\quad$ Pract., 10 : 409-424. http://www.fao.org/agris/search/display.do?f=./199 6/v2208/US9554491.xml;US9554491.

17. Hsu, R.W.W., W.H. Hsu, C.L. Tai and K.F. Lee, 2004. Effect of shock wave therapy on patellar tendinopathy in a rabbit model. J. Orthopaedic Res., 22: 221-227. http://cat.inist.fr/?aModele $=$ afficheN\&cpsidt $=1552$ 8875.

18. Johnson, M.I., 2001. Transcutaneous Electrical Nerve Stimulation (TENS) and TENS-like devices: Do they provide pain relief? Pain Rev., 8: 121-158. DOI: 10.1191/0968130201pr182ra

19. Johnson, M.I. and G. Tabasam, 2003. An investigation into the analgesic effects of interferential currents and transcutaneous electrical nerve stimulation on experimentally induced ischemic pain in otherwise pain free volunteers. Phys. $\quad$ Therap., 83: 208-223. http://www.ptjournal.net/cgi/content/abstract/83/3/ 208. 
20. Kainer, R.A., 2002. Functional Anatomy of Equine Locomotor Organs. In: Adams' Lameness in Horses, Stashak, T.S. (Ed.). 5th Edn., Lippincott Williams and Wilkins, ISBN-10: 0781741955 pp: $1-72$.

21. Lin, T.W., L. Cardenas and L.J. Soslowsky, 2004. Biomechanics of tendon injury and repair. J. Biomechan., 37: 865-877. http://linkinghub.elsevier.com/retrieve/pii/S002192 9003004068.

22. Litke, D.S. and L.E. Dahners, 1994. Effects of different levels of direct current on early ligament healing in a rat model. J. Orthopaedic Res., 12: 683-688. DOI: 10.1002/jor.1100120511.

23. Micklethwaite, L., A.K.W. Wood, C.M. Sehgal, M. Polansky, B.A. Dowling, A.J. Dart, R.J. Rose and D.R. Hodgson, 2001. Use of quantitative analysis of sonographic brightness for detection of early healing of tendon injury in horses. Am. J. Vet. Res., 62: 1320-1327.

24. Nessler, J.P. and D.P. Mass, 1987. Direct current electrical stimulation of tendon healing in vitro. Clin. Orthopaed. Relat. Res., 217: 303-312. http://www.ncbi.nlm.nih.gov/pubmed/3493869.

25. Nicoll, R.G., A.K.W. Wood and T.L.W. Rothwell, 1992. Ultrasonographical and pathological studies of equine superficial digital flexor tendons; initial observations, including tissue characterization by analysis of image grey scale in a Thoroughbred gelding. Equine Vet. J., 24: 318-320. http://www.fao.org/agris/search/display.do?f=./199 4/v2008/GB9127562.xml;GB9127562.

26. Pickersgill, C.H., C.M. Marr and S.W.J. Reid, 2001. Repeatability of diagnostic ultrasonography in the assessment of the equine superficial digital flexor tendon. Equine Vet. J., 33: 33-37. http://www.ncbi.nlm.nih.gov/pubmed/11191607.
27. Reef, V.B., 2001. Superficial digital flexor tendon healing: Ultrasonographic evaluation of therapies. Vet. Clin. North Am.: Equine Pract., 17: 159-178. http://www.ncbi.nlm.nih.gov/pubmed/11488042.

28 Stashak, T.S., 2002. Examination for Lameness. In: Adams' Lameness in Horses, Stashak, T.S., (Ed.). 5th Edn., Lippincott Williams and Wilkins, pp: 113-183.

29. Stewart, K.M., 1991. Review and comparison of current trends in the postoperative management of tendon repair. Hand Clin., 7: 447-460. http://www.ncbi.nlm.nih.gov/pubmed/1939353?do $\mathrm{pt}=$ Abstract.

30. Watson, T., 2000. The role of electrotherapy in contemporary physiotherapy practice. Manu. Therap., 5: 132-141. http://www.ncbi.nlm.nih.gov/pubmed/11034883.

31. Watson, T., 2002. Current concepts in electrotherapy. Haemophilia, 8: 413-418. DOI: 10.1046/j.1365-2516.2002.00613.x.

32. Wikstrom, S.O., P. Svedman, H. Svensson and A.S. Tanweer, 1999. Effect of transcutaneous nerve stimulation on microcirculation in intact skin and blister wounds in healthy volunteers. Scand. J. Plast. Reconstruct. Surg., 33: 195-201. http://www.ncbi.nlm.nih.gov/pubmed/10450577.

33. Wrigley, R.H., 2002. Ultrasonography of the Tendons, Ligaments and Joints. In: Adams' Lameness in Horses, Stashak, T.S., (Ed.). 5th Edn., Lippincott Williams and Wilkins, pp: 312-346. 